\title{
O INSTITUTO MULTIDISCIPLINAR DA UNIVERSIDADE FEDERAL RURAL DO RIO DE JANEIRO NO CONTEXTO DE EXPANSÃO DO ENSINO SUPERIOR DO GOVERNO LULA
}

\author{
R.A.Souza ${ }^{1 *}$; N.M.P.Souza ${ }^{1}$; \\ 1 Universidade Federal Rural do Rio de Janeiro, 23851-970, Seropédica-RJ, Brasil \\ *renanarjona@gmail.com
}

\section{RESUMO}

Este artigo se propõe a descrever parte do processo de expansão do ensino superior da Universidade Federal Rural do Rio de Janeiro - UFRRJ, a partir da criação do Instituto Multidisciplinar de Nova Iguaçu, buscando analisar o processo de implantação deste Campus (2006 a 2009). No ano de 2004, começou a se consolidar uma política de ensino superior que aumentou o investimento e promoveu a expansão e interiorização das Universidades Federais. Como parte desta expansão, para atender a região da Baixada Fluminense, o Instituto Multidisciplinar foi fruto dos objetivos de ambos os projetos de expansão. Porém, o contexto político e administrativo no qual este instituto foi criado provocou discussões sobre qualidade no ensino superior e sobre a importância das Universidades Federais como expressão das políticas do governo, buscando atender à missão e a responsabilidade social da universidade pública com seu entorno e com as populações carentes.

PALAVRAS-CHAVE: Baixada Fluminense, responsabilidade social, política publica.

\section{FEDERAL RURAL UNIVERSITY OF RIO DE JANEIRO IN THE CONTEXT OF HIGHER EDUCATION EXPANSION OF LULA GOVERNMENT}

\begin{abstract}
This article aims to describe part of the expansion process in higher education Rural Federal University of Rio de Janeiro - UFRRJ, from the creation of the Multidisciplinary Institute of Nova Iguaçu, trying to analyze the implementation process of this Campus (2006-2009). In 2004, he began to consolidate a higher education politics that increased investment and promoted the expansion and internalization of Federal Universities. As part of this expansion, to serve the
\end{abstract}

region of Baixada Fluminense, the Multidisciplinary Institute of the goals was the result of both expansion projects. However, the political and administrative context in which it was set resulted in quality discussions in higher education and the importance of Federal Universities as an expression of government policies, seeking to meet the mission and social responsibility of the public university with its surroundings and underserved populations.

KEYWORDS: Baixada Fluminense, social responsability, public politics. 


\section{INTRODUÇÃO}

Este artigo está baseado em um capítulo inicial de uma pesquisa mais ampla que se encontra em desenvolvimento sobre "o significado social da política de expansão do ensino superior para a região da Baixada Fluminense, no Estado do Rio de Janeiro", realizada a partir da implantação do Campus Nova Iguaçu da Universidade Federal Rural do Rio de Janeiro (UFRRJ), no ano de 2006 que será parte da dissertação de Mestrado em Educação Agrícola do autor Renan Arjona de Souza.

Mesmo apresentando avanços nos últimos anos, os baixos índices sociais e educacionais ainda são uma marca negativa da Baixada Fluminense. E neste estudo, esta região será analisada como espaço periférico de um centro urbano, em que os municípios constituem juntamente com o centro uma área densa chamada metrópole.

Simões (2007, p. 2) destaca um consenso que aponta Nova Iguaçu e Duque de Caxias como núcleos e os municípios de Belford Roxo, São João de Meriti, Nilópolis, Mesquita, Queimados e Japeri como componentes desta região. Magé, Guapimirim, Itaguaí, Paracambi e Seropédica nem sempre são incluídos. Por este motivo, este estudo delimita a região aos oito municípios descritos.

No ano de 2004, começou a se consolidar uma política pública de ensino superior que aumentou o investimento e promoveu a expansão e interiorização das Universidades Federais. Como parte desta expansão, a região da Baixada Fluminense foi escolhida para abrigar uma IFES como projeto de desenvolvimento social.

Paralelamente, a UFRRJ, no ano de 2004 uma instituição quase centenária, se manteve ao longo do tempo envolvida na ampliação da oferta de vagas e expansão de cursos importantes para a região e para o país. E historicamente atua através da abrangência do ensino, pesquisa e extensão no contexto socioeconômico da Baixada Fluminense, mesmo instalada no município de Seropédica.

Este artigo se propõe a descrever parte do processo de expansão do ensino superior da UFRRJ, a partir da criação do Instituto Multidisciplinar de Nova Iguaçu, buscando analisar o processo de implantação deste Campus (2006 a 2009). Assim como sua relação com esta política pública e as transformações políticas e administrativas que esta instituição vivenciou através do detalhamento da implantação deste campus universitário.

O contexto político e administrativo no qual este instituto foi criado provocou discussões sobre a qualidade no ensino superior e sobre a importância das Universidades Federais como expressão das políticas do governo, buscando atender à missão e a responsabilidade social da universidade pública com seu entorno e com as populações carentes.

\section{CONTEXTUALIZAÇÃO HISTÓRICA}

No ano de 2004, ocasião do primeiro mandato do presidente Luis Inácio Lula da Silva, do Partido dos Trabalhadores (PT), o governo já completava um ano de ações de planejamento e as primeiras medidas governamentais voltadas para a primeira etapa da expansão das Instituições Federais de Educação no Brasil começaram a serem executadas.

Na sua proposta de expansão do ensino superior, o governo Lula estabeleceu critérios que revelam as prioridades e necessidades entendidas para subsidiar as escolhas dos locais e regiões para expansão, são elas:

"a vocação da região e políticas públicas em desenvolvimento - arranjos produtivos locais;

a promoção do desenvolvimento com redução das assimetrias regionais; a localização 
geográfica; a população da micro e mesorregião atendidas; os polos da Universidade Aberta do Brasil (UAB); os indicadores de desenvolvimento econômico e social (taxas de evolução): IDH, IDEB; a taxa da oferta de vagas públicas e privadas na educação superior (estadual, federal, técnica) na microrregião e mesorregião; as áreas de formação prioritárias (formação de professores, saúde, tecnologias); o curso em área de conhecimento existente na universidade; o curso novo em área de conhecimento de ações prioritárias e a ampliação da oferta de educação superior pública no período noturno.” (BRASIL, 2015, p. 36)

Dentro destes critérios, o Governo Federal escolheu esta região central da Baixada Fluminense para receber um campus de uma universidade federal, na cidade de Nova Iguaçu-RJ. As universidades federais mais próximas eram: a Universidade Federal Fluminense (UFF), sediada em Niterói-RJ, e a Universidade Federal Rural do Rio de Janeiro (UFRRJ), com a sede principal em Seropédica-RJ.

Como pode ser visualizado na tabela abaixo, no ano de 2004, mesmo com a importância desta região, os oito municípios ainda não possuíam um campus universitário federal instalado. Observam-se apenas iniciativas das instituições federais mais próximas através de convênios e projetos de extensão. E os municípios de Mesquita e Japeri não possuíam em seus territórios nenhuma oferta de cursos de graduação.

Tabela 1 - Cursos de graduação presenciais ofertados na Baixada Fluminense - ANO: 2004

\begin{tabular}{|l|c|c|c|c|c|c|c|}
\hline \multirow{2}{*}{ Municípios* } & \multicolumn{2}{c|}{$\begin{array}{c}\text { Faculdade e } \\
\text { Centro Universitário }\end{array}$} & \multicolumn{3}{c|}{ Universidade } & CEFET / IFET & $\begin{array}{c}\text { Total de } \\
\text { Cursos }\end{array}$ \\
\cline { 2 - 9 } & $\begin{array}{c}\text { Federal e } \\
\text { Estadual }\end{array}$ & Privado & Federal & Estadual & Privado & Federal & 41 \\
\hline \hline Duque de Caxias & 0 & 7 & 0 & 4 & 30 & 0 & 37 \\
\hline Nova Iguaçu & 0 & 3 & 2 & 0 & 31 & 1 & 24 \\
\hline São João de Meriti & 0 & 0 & 1 & 0 & 23 & 0 & 13 \\
\hline Belford Roxo & 0 & 13 & 0 & 0 & 0 & 0 & 9 \\
\hline Nilópolis & 0 & 5 & 0 & 0 & 0 & 4 & 6 \\
\hline Queimados & 0 & 0 & 0 & 0 & 6 & 0 & 130 \\
\hline \hline Total & 0 & 28 & 3 & 4 & 90 & 5 & 5 \\
\hline
\end{tabular}

FONTE: MEC/INEP - Elaborada pelo autor (2015)

Analisando a tabela 1 percebemos uma grande quantidade de cursos de graduação ofertados por instituições privadas. Este domínio se dava principalmente pela pouca oferta de cursos e vagas oferecidas por instituições públicas.

Porém, mesmo com a predominância da oferta de cursos de graduação privados, é importante destacar os esforços empreendidos no contexto de atuação das instituições públicas referente à oferta de cursos de graduação presenciais no ano de 2004, pois, apesar das dificuldades, estas buscaram alternativas e se fizeram presentes nesta região direta ou indiretamente em projetos não somente em ensino, mas também em pesquisa e extensão.

A Universidade Federal Fluminense (UFF) realizava através de convênios com as prefeituras locais a oferta de dois cursos de graduação: um em Nova Iguaçu (desde 1992) e um em São João de Meriti (desde 2002). 
A Faculdade de Educação da Baixada Fluminense (FEBF), uma unidade da Universidade do Estado do Rio de Janeiro (UERJ), ofertava quatro cursos de graduação nas instalações do antigo CIEP 090- cedido à FEBF, em Duque de Caxias.

A Escola Técnica Federal de Química-RJ (ETFQ), que saiu do Centro Federal de Educação Tecnológica Celso Suckow da Fonseca do Rio de Janeiro (CEFET-RJ) em 1985, teve sua denominação alterada quando da criação do Sistema Nacional de Educação Tecnológica (Lei 8.948, de 8 de dezembro de 1994), que previa às escolas técnicas federais serem alçadas à categoria de CEFET.

Então, ao ter as suas finalidades ampliadas em 1999, a ETFQ que estava sediada no Maracanã-RJ mudou sua sede para o município de Nilópolis e se transformou em Centro Federal de Educação Tecnológica de Química de Nilópolis - RJ, por exigência da Lei 8.948, de 8 de dezembro de 1994, que previa às escolas técnicas federais serem alçadas à categoria de CEFET.

Em 2004, o então CEFET Química de Nilópolis, hoje denominado como Campus do Instituto Federal do Rio de Janeiro (IFRJ), ofertava os cursos superiores de licenciatura em Química, Licenciatura em Física, Tecnologia em Química de Produtos Naturais e Tecnologia em Produção Cultural. (IFRJ PDI 2009-2013, p. 23).

O CEFET-RJ é uma instituição voltada a uma formação profissional que deve ir ao encontro da inovação e do desenvolvimento tecnológico, da modernização industrial sem perder de vista a dimensão social do desenvolvimento. Por vocação histórica e atuação na educação tecnológica, responde aos objetivos de ensino, pesquisa e extensão, sem exclusão de níveis de ensino ou de segmentos acadêmicos. Por este motivo, a comunidade desta instituição pleiteia uma proposta que consolide o crescimento institucional atingido, apresentando-se, assim, a proposta de transformação do CEFET-RJ em Universidade Especializada. (CEFET-RJ PDI 2010-2014, p. 17)

Em 2004 o CEFET-RJ contava com uma unidade-sede (Maracanã), dois campi (General Canabarro e Maria da Graça, ambos ligados à unidade-sede) e uma unidade descentralizada de ensino em Nova Iguaçu (inaugurada oficialmente em 22 de agosto de 2003) que até hoje oferece quatro cursos técnicos em concomitância com o ensino médio. (CEFET-RJ PDI 2005-2009, p. 12)

No ensino superior, nas instalações do CEFET - UnEd Nova Iguaçu, no bairro de Santa Rita, começaram a serem oferecidos dois cursos de graduação noturnos, de Engenharia Industrial de Controle e Automação do próprio CEFET e a instituição cedeu suas instalações para duas turmas do Curso de Graduação de Administração da UFRRJ, mediante projeto estabelecido no âmbito do Ministério da Educação para o desenvolvimento de um projeto de Universidade Pública na Baixada Fluminense, em ação consorciada entre as instituições federais de ensino UFF, UFRRJ e o CEFETRJ.

Para funcionamento destes cursos, o consórcio estabelecia que o vestibular fosse realizado em conjunto, conduzido pela UFRRJ, e começaram a funcionar em setembro de 2004. O curso de Economia diurno da UFF, também integrante do consórcio, foi oferecido no Centro de Direitos Humanos da Diocese de Nova Iguaçu, localizada na Rua Capitão Chaves.

O chamado Consórcio de Universidades Públicas administrava os cursos através de um grupo composto pelos reitores e diretores de unidades das sedes, em que a comunidade tinha dois representantes. Além de formular as diretrizes para a criação de uma Universidade Pública na Baixada Fluminense, o consórcio foi encarregado de supervisionar o gasto público relativo à implantação destes cursos, cujo financiamento proveio da emenda parlamentar Lindberg Farias (BRASIL, 2003). 
O Consórcio, criado em 2004, foi extinto em 2005, e substituído pela proposta governamental de implantação de um campus da UFRRJ, que foi denominado Instituto Multidisciplinar, conforme ofício n ${ }^{\circ}$ 2292/2005 MEC/SESu/DEDES, de 12 de abril de 2005, que deu origem ao Convênio entre Governo Federal e UFRRJ.

O Projeto Político Pedagógico inicial do Instituto Multidisciplinar revela parte do contexto em que a proposta inicial de criação de uma Universidade Pública na Baixada Fluminense foi formulada pelo Fórum pela Universidade Pública da Baixada Fluminense, em março de 2004, sob a liderança da Câmara de Vereadores de Nova Iguaçu. Essa proposta teve como modelo a Escola de Governo da Baixada Fluminense, um consórcio de professores de várias universidades e instituições do Estado do Rio de Janeiro (UFF, UFRRJ, UERJ, ENCE, IBGE, CPDOC, PUC e Fundação CIDE do Estado do Rio de Janeiro) que já funcionava em São João de Meriti e Nova Iguaçu, desde 2003, envolvendo ensino, pesquisa e extensão.

A criação de uma Escola de Governo da Baixada Fluminense (EGBF), um projeto de extensão da UFF em parceria com outras instituições e entidades, juntou professores e técnicos de diferentes instituições do Estado do Rio de Janeiro pelo objetivo de estabelecer uma estrutura de ensino e pesquisa, que fosse o primeiro passo para a constituição de um núcleo de excelência em estudos da Baixada Fluminense, contemplando formação técnica, ensino de graduação e pesquisa, verdadeiro embrião de uma Universidade Pública na região.

Assim, a constituição do hoje Instituto Multidisciplinar da UFRRJ, que se autodenomina herdeiro dos anseios da população por uma instituição pública de nível superior que atendesse às suas necessidades loco regionais, originou-se do trabalho de um Fórum democrático, processo inédito na história da universidade brasileira.

As reuniões em torno da proposta de uma Universidade Pública começaram a ser realizadas no final de 2002, na Secretaria de Desenvolvimento da Baixada Fluminense, envolvendo mais de 500 pessoas. Nestes encontros participaram professores destas universidades, lideranças locais, vereadores, associações de profissionais e comerciais, além de outros atores da sociedade civil.

A EGBF se estruturou de forma independente, com apoio financeiro da FAPERJ, que concedeu bolsas para professores associados e visitantes, apoio técnico e iniciação cientifica. Foi criado um Programa de Formação Comunitário de níveis médio e superior, inspirado nas demandas da região da Baixada Fluminense, tendo em primeiro lugar, a gestão pública como um de seus focos principais de atuação.

A EGBF criou um curso com duração de cinco meses de Introdução às Ciências Sociais em São João de Meriti, e outro em Nova Iguaçu, com as primeiras turmas iniciadas no segundo semestre de 2003. O curso tinha por objetivo capacitar interessados em obter conhecimentos sobre os aspectos econômicos, políticos, sociais e culturais da Baixada Fluminense e desenvolver estudos sobre a região, e chegou a envolver mais de 280 alunos.

Com o objetivo era qualificar profissionais para o desempenho consciente e crítico de suas funções, a EGBF promoveu formação e qualificação, bem como capacitação e treinamento técnicos, voltados para um público primordialmente local, como lideranças políticas e comunitárias, funcionários e servidores públicos, professores do ensino médio, quadros técnicos e executivos de prefeituras de municípios da Baixada Fluminense.

Em torno desta experiência e a partir deste movimento se constituiu o Fórum PróUniversidade Pública na Baixada Fluminense, coordenado pelo vereador do município de Nova Iguaçu Carlos Ferreira, o "Ferreirinha do PT", que no final de 2003 passou a reunir-se na Câmara de Vereadores de Nova Iguaçu e atuou na mobilização da população da região debatendo o assunto em várias audiências públicas. 
Esse Fórum chegou colher 80 mil assinaturas em um abaixo assinado e a lista com as assinaturas foi entregue ao Ministério da Educação (MEC). Esta demanda popular foi fundamental para chamar a atenção do MEC e para garantia de recursos obtidos com a emenda parlamentar do deputado federal Lindberg Farias, que deu inicio ao Consórcio Universidade Pública da Baixada.

\section{MATERIAIS E MÉTODOS}

Para atingir o objetivo específico abordado neste artigo foi realizada uma pesquisa bibliográfica e documental para detalhar a história e a expansão da UFRRJ, e o contexto da política pública que promoveu a implantação do Campus Nova Iguaçu.

Além disso, também foram coletados subsídios para esta pesquisa, tais como: a análise de indicadores estatísticos, documentos e registros da UFRRJ, do Ministério da Educação, oficiais da cidade de Nova Iguaçu, publicações, e arquivos particulares, para fins de detalhar historicamente a implantação deste campus universitário.

Quanto a estes tipos de documentos, geralmente não receberam tratamento analítico, e conforme destaca Gil (2008, p. 88), “é necessária análise dos seus dados, feita em observância aos objetivos e ao plano da pesquisa”.

A estratégia de análise de conteúdo será a construção iterativa de uma explicação, onde o pesquisador elabora pouco a pouco uma explicação lógica do fenômeno ou da situação estudados, examinando as unidades de sentido, as inter-relações entre essas unidades e entre as categorias em que elas se encontram reunidas (GIL 2008, p. 90).

\section{RESULTADOS E DISCUSSÃO}

A Universidade Federal Rural do Rio de Janeiro (UFRRJ), uma instituição centenária, é originária da Escola Superior de Agricultura e Medicina Veterinária (ESAMV), vinculada inicialmente ao Ministério da Agricultura, Indústria e Comércio (MAIC). Desde a sua origem, independente das transformações e incorporações que passou ao longo da sua história, foi importante para o ensino e pesquisa para a agronomia no Brasil.

Para este trabalho foi importante destacar a sua história a partir do golpe militar instituído no Brasil em 1964. Pois após a sua posse, o primeiro presidente militar, General Arthur da Costa e Silva, promoveu duas reuniões em Brasília com o objetivo de transferir as Universidades Agrícolas para o MEC.

Em 19 de maio de 1967, o Decreto no 60.731 transferiu para o Ministério da Educação e Cultura (MEC) os órgãos de ensino do Ministério da Agricultura. Além disso, o mesmo dispositivo legal estabeleceu uma nova denominação para as três instituições afetadas, dentre elas a Universidade Rural do Brasil (URB), que passou a ser chamada por Universidade Federal Rural do Rio de Janeiro (UFRRJ). (Otranto, 2007, p. 2).

Diante das mudanças que o Governo Militar promoveu na educação do país, a Lei ${ }^{\circ}$ 5.540/68, conhecida como "Lei da Reforma Universitária", estabelecia que as Universidades deveriam ser organizadas pela "universalidade de campo, pelo cultivo das áreas fundamentais dos conhecimentos humanos", ou seja, a UFRRJ, que na época somente oferecia cursos na área agronômica, precisaria incorporar cursos das áreas de Educação e Ciências Sociais, se pretendesse continuar a ser uma Universidade. 
Então, em 1968, o Conselho Universitário da UFRRJ elaborou o Plano de Reestruturação da Universidade Federal Rural do Rio de Janeiro, que traçou diretrizes para o Estatuto da Instituição. Neste plano, além da reestruturação administrativa, encontrava-se o novo Instituto de Educação e Ciências Sociais.

O Estatuto da UFRRJ, aprovado em 1972, trouxe o Instituto de Educação separado do Instituto de Ciência Humanas e Sociais. A criação do Departamento de Educação Física, Esportiva e Recreativa, foram exigências do Ministério da Educação.

A intenção do regime militar era de promover prática da educação física, não só para ocupar os estudantes com atividades consideradas "não subversivas", como também para demonstrar que as universidades brasileiras poderiam formar atletas competitivos, como as demais instituições dos outros países. (Id., p. 5)

Mesmo diante de protestos da comunidade acadêmica da UFRRJ, esses acontecimentos foram determinantes para uma expansão gradual dos seus cursos de graduação e pós-graduação. E neste período de pouco mais de 30 anos, ela evoluiu de uma instituição de pequeno porte com cerca de 2000 alunos de graduação no final dos anos 1970 para uma instituição de médio porte, com cerca de 8000 alunos no ano 2000 (PDI da UFRRJ, 2006-2010, p.16).

A UFRRJ também expandiu vagas ao firmar convênio com as prefeituras de Paracambi, Quatis, Três Rios e Volta Redonda. Somente no período entre 1994 e 2006, entre novos cursos, ampliação de vagas dos cursos tradicionais e convênios, a UFRRJ chegou a ampliar em $72 \%$ o número de vagas oferecidas e de ingressantes. Estes números revelam que esta Universidade se manteve ao longo do tempo envolvida na ampliação da oferta de vagas e expansão de cursos importantes para a região e para o país.

A UFRRJ ampliou sua atuação nesta região com a chegada do Campus Nova Iguaçu, objeto deste estudo, mas historicamente desenvolve atividades de ensino, pesquisa e extensão no contexto socioeconômico da Baixada Fluminense, mesmo quando estava instalada apenas no município de Seropédica, atendendo a população do entorno desta área e desenvolvendo projetos sociais e educacionais diversos.

Diante deste quadro que envolveu a decisão do Governo Federal em expandir o ensino superior público, da mobilização popular em prol de uma universidade pública na Baixada Fluminense e a disposição da UFRRJ em expandir, o Governo Federal manifestou a intenção em instalar um campus universitário Federal na cidade de Nova Iguaçu-RJ.

A UFRRJ participou desta primeira proposta de expansão do Governo Federal e foi levada a produzir impactos locais e regionais, atendendo novas demandas relacionadas aos princípios da responsabilidade social e ambiental, conforme estabelecido em documentos internos da Instituição que norteiam a expansão. (UFRRJ PDI 2013-2017).

Então concedeu à UFRRJ a administração do Pólo Universitário em Nova Iguaçu revelado no Ofício $n^{\circ}$ 2292/2005 MEC/SESu/DEDES, de 12 de abril de 2005, atendendo ao protocolo de intenções assumido por esta Universidade, sua sintonia com as políticas do Governo e seu contexto histórico propício à expansão. Dentro da proposta do processo de expansão, a UFRRJ descreve a sua concepção de educação superior como:

"uma relação dialógica entre formação profissional, produção de conhecimento e função social da Universidade (ensino, pesquisa e extensão), tendo como objetivo maior a superação das desigualdades sociais, marcantemente vivenciadas nos espaços populares". (MEC, UFRRJ, Projeto Implantação do Campus Nova Iguaçu - Plano de Trabalho, 2005) 
Porém, internamente, o impacto desta expansão trouxe para esta universidade nos anos seguintes, complexos desafios no tocante à absorção de um crescimento substancial na oferta de cursos, como pode ser verificado na Tabela 2 sobre a oferta de vagas nos cursos de graduação desta instituição.

Tabela 2 - Vagas ofertadas pelos cursos de graduação presenciais da UFRRJ

\begin{tabular}{|l|c|c|c|}
\hline & $\mathbf{1 9 9 4}$ & $\mathbf{2 0 0 4}$ & $\mathbf{2 0 0 6}$ \\
\hline Campus Seropédica & 1240 & 1470 & 1540 \\
\hline Campus Nova Iguaçu & 0 & 0 & 500 \\
\hline
\end{tabular}

FONTE: PDI da UFRRJ 2006-2010, p. 38 - Adaptado pelo autor.

Na tabela 2 demonstrou-se o impacto da chegada do Campus Nova Iguaçu dentro do processo de expansão da instituição. A UFRRJ já apresentava um processo gradual de expansão e destaca-se que o campus de Nova Iguaçu representou um aumento em aproximadamente um terço das vagas oferecidas pela Universidade no ano de 2006.

As metas do programa governamental do Governo Federal de expansão do ensino superior impactaram diretamente o planejamento e as estratégias da UFRRJ no tocante ao enfrentamento deste desafio. Deste modo, consideramos o investimento financeiro direto nas IFES e a relação matrículas/docente como os principais aspectos a serem alcançados. O relatório da Secretaria de Ensino Superior (SESu) do MEC sobre a democratização e expansão do ensino superior no país destaca o investimento realizado na reposição do quadro docente, revelando um aumento quantitativo e também qualitativo pautado na elevação do número de doutores.

No Brasil como um todo, o percentual de doutores no quadro docente da educação superior cresceu de 21,4\% em 2003 para 33\% [em 2013]. O percentual de professores mais titulados (doutores e mestres) cresceu em todas as regiões do país, diminuindo, ano após ano, o percentual de docentes menos titulados (especialistas) atuantes em todas as regiões. (BRASIL, 2015, p. 26)

$\mathrm{Na}$ UFRRJ, entre os anos de 2005 e 2006 foram contratados 122 professores efetivos mediante concurso público, sendo deste total, 70 para suprirem os novos cursos ofertados no Campus Nova Iguaçu (PDI da UFRRJ, 2006-2010). As novas contratações foram realizadas dentro da proposta estatal, docentes em sua maioria doutores com dedicação exclusiva. Tais qualificações são indício não só de maior conhecimento na área lecionada como também de dedicação à pesquisa, atividade indissociável do ensino.

Ainda em relação ao aumento e qualificação do quadro docente, no planejamento da expansão em 2003, o Grupo de Trabalho Interministerial (GTI), encarregado de analisar a situação atual e apresentar plano de ação visando a reestruturação, desenvolvimento e democratização das IFES, já apontava a defasagem do quadro docente oriundo da década de 1990. Em que, até então, para superar tal lacuna, tem sido utilizada a contratação por concurso simplificado do professor substituto, contratados em caráter provisório, sem vínculo profissional permanente e sem estabilidade.

Com base na previsão da relação aluno/professor, o número ideal de professores para atender aos 1.200.000 alunos previstos para 2007 seria de 67.000. Portanto, para corrigir ao mesmo tempo a falta de professores e a substituição dos temporários por professores permanentes, seria preciso contratar 25.785 professores: 8.886 para substituir os atuais contratados como temporários, 9.211 para completar o quadro de 50.426 vagas, e 7.688 novos professores, necessários para atender ao aumento de 600 mil para 1,2 milhão de estudantes. (GTI, 2003). 
Diante deste quadro, precisando viabilizar a expansão do número de vagas de graduação e sem motivação financeira para chegar ao número ideal de docentes doutores efetivos, outras estratégias foram utilizadas, como: aumento da dedicação em sala de aula, maior número de discentes por turma e uso de técnicas de ensino à distância.

Em função disso, ocorreu neste período uma série de debates nacionais sobre a precarização do processo de expansão e interiorização das IFES. Ao participar diretamente da política de expansão, a comunidade acadêmica da UFRRJ também discutiu internamente esta pauta. O tradicional periódico da UFRRJ chamado Rural Semanal, na sua edição número 28 do ano de 2004, noticiava que nos dias 5 e 6 de outubro, por exemplo, a Associação dos Docentes da Universidade Rural (ADUR) e o Diretório Central dos Estudantes (DCE) realizariam um seminário sobre a reforma universitária.

Após várias audiências pelo país, o Sindicato Nacional dos Docentes das Instituições de Ensino Superior (ANDES-SN) elaborou um documento contra a reforma da educação superior, destacando que as mudanças caminhavam em direção contrária ao propósito de uma educação pública, gratuita e de qualidade.

Fica evidente, pela análise do citado documento e dos demais projetos que estão sendo aprovados em Brasília, que a reforma da educação superior que vem sendo implementada pelo governo Lula articula várias frentes: o conteúdo político-pedagógico; a estrutura departamental; o financiamento; a avaliação; a gestão; a autonomia universitária e a carreira docente. Essa reforma favorece os empresários da educação em crise em busca de novos campos de exploração, tornando a educação um dos mais lucrativos setores de investimentos para empresários brasileiros e estrangeiros. (ANDES, 2004, p. 22).

Dentro deste debate os números referentes ao quadro docente foram um dos argumentos dos que ressalvavam esta política e os desafios a serem enfrentados pela UFRRJ ao aderir ao processo de expansão. A docente e pesquisadora da UFRRJ, professora Dra. Célia Otranto, ao escrever sobre o quadro docente da política da educação superior do governo Lula, percebeu características de uma concepção de universidade descrita pelos documentos do Banco Mundial centrada somente no ensino em contraposição à pesquisa e pós-graduação, e na quantidade em detrimento da qualidade.

Em seu trabalho a pesquisadora destacou que "instituições universitárias voltadas ao ensino e cursos superiores de curta duração [...] são consequências dessas indicações [do Banco Mundial], que inspiraram a LDB de 1996 e legislação complementar." Com isso revela esta influência em vários pontos da proposta de expansão do Governo Federal, pautada no estudo realizado pelo GTI.

\begin{abstract}
Mesmo mencionando a necessidade da abertura de concursos para preencher as vagas de professores e servidores, o GTI apresenta como alternativa para fazer frente à demanda, a criação de novas bolsas da CAPES, para aproveitar aposentados e recém doutores nas atividades de ensino de graduação. Na sequência, propõe o aumento da carga horária dos professores em sala de aula, o aumento no número de alunos e a educação à distância. (Otranto, 2006, p. 2)
\end{abstract}

A UFRRJ, como uma autarquia federal, vivenciou um período de poucos investimentos públicos nas IFES, em função da política de contenção de gastos, principalmente no período do governo do presidente Fernando Henrique Cardoso (1995 a 2002). E mesmo com o crescimento da oferta de vagas discentes no ensino superior neste período, o número de docentes efetivos da UFRRJ (contratados via concurso público) reduziu de 553 professores no ano de 1994, para 468 professores no ano de 2004, ou seja, sofreu redução de $15,4 \%$. Este aspecto afetou diretamente a oferta de disciplinas dentro do aumento de oferta de vagas. 
Esta falta de reposição, reflexo de uma política nacional de redução de investimentos nos órgãos públicos trouxe graves dificuldades e distorções para o adequado funcionamento e à qualidade dos cursos de graduação (PDI 2006-2010). Os novos docentes foram contratados exclusivamente para os novos cursos e chegaram também para suprirem uma carência de falta de professores.

Somente a correção da defasagem de anos de sucateamento das IFES demandaria uma necessidade de política pública para melhorar as condições de oferta da educação superior, mas o governo federal escolheu expandir quantitativamente a universidade. Esta decisão talvez tenha sido motivada pela mudança de liderança política causada com a chegada do Partido dos Trabalhadores ao poder e também pela história política do Brasil, que mostra a preferência dos governantes, em geral, por programas partidários que promovem mais popularidade em detrimento de programas de Estado com caráter efetivo.

Esta discussão também perpassava pelo funcionalismo técnico administrativo, com debates sobre o processo de terceirização de atividades meio das IFES que acontecia no país à época e ainda ocorre hoje. Não somente na contratação de novos servidores, outro aspecto em análise é que o programa de expansão do governo federal possibilitou à UFRRJ aumentar receita para execução do seu orçamento e assim viabilizar a implantação do novo campus e outros projetos internos relacionados à expansão. Por este motivo, os recursos financeiros investidos na expansão e interiorização das IFES se constituem em outro fator a ser considerado neste contexto, especialmente na UFRRJ.

A tabela 3 mostra os orçamentos federais no período entre os anos 2002 e 2009. Ela resgata o último ano de mandato do presidente Fernando Henrique Cardoso (2002), que destinava recursos específicos para a modernização e recuperação de IFES, porém um valor considerado simbólico em termos absolutos. E também demonstra o crescimento deste investimento na UFRRJ ao longo do primeiro mandato do presidente Luis Inacio Lula da Silva (2003 a 2006). Nesta tabela podemos visualizar o crescimento do orçamento total da UFRRJ na Lei Orçamentária Anual (LOA) no período e o peso do "Projeto Nova Iguaçu" na composição de todo o Investimento nesta Universidade, compreendido principalmente entre os anos 2007 e 2009.

Tabela 3 - Orçamentos da UFRRJ 2002-2009

$\mathrm{R} \$ 1,00$

\begin{tabular}{|l|c|c|c|c|c|c|c|c|}
\hline \multicolumn{1}{|c|}{ UFRRJ } & $\mathbf{2 0 0 2}$ & $\mathbf{2 0 0 3}$ & $\mathbf{2 0 0 4}$ & $\mathbf{2 0 0 5}$ & $\mathbf{2 0 0 6}$ & $\mathbf{2 0 0 7}$ & $\mathbf{2 0 0 8}$ & $\mathbf{2 0 0 9}$ \\
\hline $\begin{array}{l}\text { Orçamento } \\
\text { Total (LOA) }\end{array}$ & 98.925 .323 & 111.013 .754 & 117.977 .321 & 148.647 .861 & 165.344 .343 & 195.168 .834 & 205.998 .800 & 218.527 .476 \\
\hline $\begin{array}{l}\text { Modernização e } \\
\text { Recuperação da } \\
\text { Infra-estrutura } \\
\text { Física das IFES }\end{array}$ & 750.000 & 750.000 & 989.983 & 1.176 .785 & 2.304 .848 & 3.100 .000 & $\begin{array}{c}500.000 \\
300.000 \\
\text { Campus NI }\end{array}$ & $\begin{array}{c}1.674 .950 \\
8.975 .100 \\
\text { Campus NI }\end{array}$ \\
\hline $\begin{array}{l}\text { Projeto Nova } \\
\text { Iguaçu }\end{array}$ & $\mathrm{X}$ & $\mathrm{X}$ & $\mathrm{x}$ & $\mathrm{x}$ & $\mathrm{x}$ & 6.168 .020 & 3.404 .822 & 3.402 .858 \\
\hline
\end{tabular}

FONTE: BRASIL/SECRETARIA DE ORÇAMENTO FEDERAL - Orçamentos da União

O crescimento de mais de $100 \%$ no orçamento da UFRRJ em oito anos revela claramente a proposta do governo em atender aos seus objetivos de expansão e recuperação da infraestrutura desta Universidade. Os recursos eram destinados à recuperação da infraestrutura e investimento em novas instalações para abrigar os novos cursos. Cabia então à gestão da UFRRJ o desafio de aplicar os recursos visando o melhor aproveitamento possível, e ao longo dos anos, estudos sobre as consequências poderiam mostrar se, de fato, esta proporção de investimento seria suficiente. 
O GTI reconhece já no plano de ação realizado que os recursos visando à manutenção e recuperação das universidades contempladas pelo programa seriam insuficientes. "O montante de recursos previsto no Projeto de Lei para o ano de 2004 é de R\$ 557 milhões, faltando assim, segundo o MEC, R\$ 202 milhões para atender às necessidades das universidades.” (Brasil, 2003).

Diante de todo este contexto foi oficializada na $210^{\mathrm{a}}$ reunião ordinária do Conselho Universitário da UFRRJ (CONSU), realizada no dia 20 de julho do ano de 2005, a unidade de Nova Iguaçu. Esta unidade foi chamada Instituto Multidisciplinar, e nasceu como o décimo instituto desta instituição, ofertando inicialmente seis cursos de graduação presenciais, destes, três licenciaturas (Matemática, Pedagogia e História) e três bacharelados (Turismo e Hotelaria, Administração e Ciências Econômicas).

Tratado com um campus universitário pela política pública de expansão, a UFRRJ decidiu por instituí-lo como mais um dos seus institutos, este, entretanto, fora de sede. O termo multidisciplinar foi cunhado em função da diversidade de áreas a serem contempladas nos cursos oferecidos. O reconhecimento como Campus Nova Iguaçu da UFRRJ só aconteceu com a reforma do Estatuto e do Regimento Interno da UFRRJ, aprovada no ano de 2012. Por este motivo, neste trabalho será utilizado o termo Instituto Multidisciplinar.

O Instituto Multidisciplinar foi estruturado inicialmente em quatro departamentos didáticocientíficos: Departamento de Educação e Sociedade, abrigando o curso de Pedagogia; Departamento de História e Economia, abrigando os cursos de História e Ciências Econômicas; Departamento de Tecnologias e Linguagens, abrigando o curso de Matemática e Departamento de Administração e Turismo, abrigando os cursos de Administração e Turismo.

Dada a autorização pelo Conselho Universitário da UFRRJ, a instituição iniciou as tarefas administrativas para a viabilização do novo campus. Foram realizados ajustes no Estatuto e Regimento Geral para alocar o novo instituto e foi designada uma diretora pro tempore para administra-lo, professora Dra Lucília Augusta Lino de Paula, designada pela Portaria $n^{\circ} 788 / G R$, de 14 de outubro de 2005. Depois ratificada no cargo através da portaria nº 802 de 20/09/2006.

Os valores do projeto de viabilização foram gerenciados pela Fundação de Apoio a Pesquisa Científica e Tecnológica da Universidade Rural (FAPUR), através do termo de cooperação técnica $n^{\circ} 28 / 2005$, publicado no Diário Oficial da União em 14 de outubro de 2005, e homologado na $213^{\text {a }}$ Reunião Ordinária do Conselho Universitário, realizada em 4 de novembro de 2005.

A UFRRJ, então, elaborou o "Projeto de Implementação do Campus da UFRuralRJ em Nova Iguaçu" que contemplava o Projeto Político Pedagógico e o Projeto Arquitetônico das Instalações Físicas, que integram o processo administrativo número 23083.004855/2005-55.

Os recursos do estudo de viabilização do novo campus permitiram a execução das atividades iniciais de implantação, como o diagnóstico junto à comunidade de Nova Iguaçu e a elaboração do Projeto Político Pedagógico. Neste documento, também se encontra um projeto de pesquisa orientada realizada junto a jovens e adultos de Nova Iguaçu que concluíram o ensino médio e a estudantes secundaristas das escolas de nível médio da cidade acerca das suas expectativas em relação ao ingresso no ensino superior e aos cursos em que pretendem se candidatar. Os seguintes docentes conduziram as etapas da pesquisa orientada: Tânia Ventura da Silva B. Santos; José Airton Cavalcanti Junior; Lana Claudia da Fonseca; Suely Conceição de Lima Soares; Diana Veiga Mandelert; Helena de Carvalho; Roberto Guanabara.

A pesquisa também contou com o apoio de dez bolsistas da Instituição: Alfredo Carvalho da Silva; Amanda Moreira da Silva; Amanda Macedo Singulani; Joice Caetano Resende; Juliene Paes Leme de Oliveira; Maura Rodrigues de Almeida; Regiane de Souza Costa; Thaiane Cavalcanti Couto; Paulo Thiago Neves dos Santos; Viviane Cristina Silva Lima. 
Esta pesquisa somada a dados censitários e os estudos junto à Secretaria Municipal de Educação da cidade de Nova Iguaçu quanto às necessidades de formação da população, permitiria identificar alguns cursos com maior interesse por parte da sociedade. Cabe ressaltar que o projeto de pesquisa orientada já destacava uma demanda prioritária da região por cursos de formação de professores, dada a necessidade de elevação da qualidade de ensino das escolas públicas para o desenvolvimento da Baixada Fluminense.

O Projeto Arquitetônico das Instalações Físicas do IM Campus da UFRRJ- Nova Iguaçu inicial previa um orçamento preliminar de construção de $\mathrm{R} \$ 13.256 .000,00$ (treze milhões e duzentos e cinquenta e seis mil reais). As instalações físicas ocuparam a área de 35 mil metros quadrados na Rua Governador Roberto Silveira, sem número, entre o Areoclube de Nova Iguaçu e a Rodovia Presidente Dutra, conforme previsto na proposta original.

Devido ao pouco tempo hábil e a ainda incipiente construção das instalações do campus a UFRRJ firmou parceria com a Prefeitura de Nova Iguaçu permitindo ao recém-criado instituto funcionar provisoriamente no Colégio Municipal Monteiro Lobato, com cinco salas cedidas para trabalho administrativo e uso de todas as salas do colégio para aulas, no período noturno.

A aula inaugural do Instituto Multidisciplinar ocorreu somente em 17 de abril de 2006, na quadra da Vila Olímpica, ao lado do Colégio Municipal Monteiro Lobato, feita para recepcionar os primeiros 250 estudantes matriculados nos seis cursos de graduação: Administração, Turismo e Hotelaria, Economia, Pedagogia, História e Matemática (licenciatura/bacharelado).

A inauguração se tornou um evento na região, com apresentação do coral da UFRRJ e aula magna intitulada "Universidade, Sociedade e Formação Profissional: inclusão social e desenvolvimento sustentável". Das 158 pessoas presentes, muitas eram autoridades que marcaram presença, como: prefeito Lindberg Farias do município de Nova Iguaçu, Vereador Carlos Ferreira (Nova Iguaçu); Vereador Taffarel (Mesquita); representantes das Secretarias de Educação, Juventude e Esporte da Prefeitura de Nova Iguaçu; representantes da Câmara Municipal de Nova Iguaçu; representantes da Prefeitura de Seropédica; Diretoras do Colégio Municipal Monteiro Lobato; Reitor Ricardo Motta Miranda da UFRRJ, Pró-Reitores e Diretores de Instituto da UFRRJ.

No dia da sua inauguração oficial, o Instituto Multidisciplinar de Nova Iguaçu contava com sete técnicos administrativos: dois em nível de ensino superior, Eduardo Luiz de Sousa (administrador) e Fernanda Borges Vaz (bibliotecária); e cinco em nível de ensino médio, Diná Andrade Lima Ramos, Fabio Antonio Abreu da Silva, Hugo Neves Delgado, Kate Hellen de Sousa Batista e Mariana Gomes de Oliveira.

O ano de 2006 foi um ano de consolidação das instalações e solidificação das atividadesmeio da UFRRJ. Ao fim deste ano, o Instituto Multidisciplinar de Nova Iguaçu já contava com dezenove técnicos administrativos.

Com o crescimento do quadro discente a cada semestre letivo, as instalações do Colégio Municipal Monteiro Lobato ficaram pequenas para o funcionamento do novo campus universitário. Então, no ano de 2008, havendo a necessidade de se conseguir um lugar maior para instalá-la integralmente, a administração superior da UFRRJ alugou o prédio da Diocese, situado à Rua Capitão Chaves, $n^{\circ}$ 60, Centro, Nova Iguaçu-RJ.

Naquele tempo, o Instituto Multidisciplinar ocupava não apenas um, e sim dois prédios provisórios, o do Colégio Municipal Monteiro Lobato e o da Diocese de Nova Iguaçu, mas no prédio da Diocese havia a possibilidade de ofertar cursos durante o dia e à noite.

Mesmo utilizando dois prédios provisórios, as instalações do Instituto Multidisciplinar já estavam no limite, e a partir do ano de 2009 houve a necessidade de alugar um terceiro prédio. 
Então a universidade utilizou parte da estrutura do Colégio Leopoldo, um colégio particular situado na Avenida Getúlio de Moura, nº 1074, também no centro de Nova Iguaçu.

Em junho de 2009, tomou posse a nova diretora do Instituto Multidisciplinar de Nova Iguaçu, a professora Dra Leila Dupret Machado. Escolhida pela comunidade acadêmica do Instituto através de votação, ela foi oficializada pela Reitoria da Universidade para um mandato de quatro anos (junho de 2009 a junho de 2013).

O Instituto Multidisciplinar vivia, então, a realidade de existir em três prédios distantes em um quarteirão, com aulas acontecendo prioritariamente no período noturno, mas funcionando ativamente durante todo o dia. Esta situação ocorreu até o primeiro semestre do ano de 2010, em que por força da ação de docentes, funcionários e da direção do instituto decidiram se transferir para o campus definitivo, mesmo com as instalações ainda em término de construção, fruto de atrasos na execução da obra.

Diante do enfrentamento destas dificuldades, muitos debates ocorreram no Instituto Multidisciplinar no sentido de posicionamento diante das instâncias superiores da UFRRJ e do Governo Federal para obter mais investimentos. Paralelamente aos anos iniciais de funcionamento do Campus Nova Iguaçu da UFRRJ (2006-2009), os recursos referentes à implantação das instalações físicas foram realizados dentro de um plano de trabalho de execução compreendido entre novembro de 2005 e dezembro de 2007, documentada no convênio número 121/2005, celebrado entre a União e a UFRRJ em oito de dezembro de 2005.

A história de funcionamento destes primeiros quatro anos de existência do Instituto Multidisciplinar de Nova Iguaçu, fruto de superação da gestão da UFRRJ e dos docentes, técnicos e discentes envolvidos, traz o contexto da oferta de ensino superior para esta região, fruto da política pública de expansão.

\section{CONCLUSÃO}

De acordo com dados do sistema acadêmico da UFRRJ, no final do ano de 2009 o Instituto Multidisciplinar de Nova Iguaçu já contava com 128 docentes efetivos, aproximadamente 60 técnico-administrativos e 1677 estudantes de graduação presenciais, dos seis cursos de graduação, o que demonstra um crescimento importante para a região.

Dentro de quatro anos, estes números revelam significativo crescimento em ofertas de vagas, docentes, pessoal administrativo e infraestrutura. Deste modo, é importante considerar que um processo de implantação de um campus universitário desta magnitude, dentro das condições descritas, naturalmente necessita um tempo maior para consolidação.

E mesmo diante das instalações provisórias, transformações políticas e administrativas vivenciadas neste período, se criou um ambiente para atender aos objetivos do Governo Federal, que almejava "o desenvolvimento regional, por meio da integração com a comunidade local e da participação efetiva das universidades no desenvolvimento da formação profissional e pesquisa regionais". (BRASIL, 2015, p. 37).

As discussões sobre a qualidade do ensino superior oferecida pelas IFES, que poderia ficar comprometida dentro deste processo de expansão, são importantes para chamar a sociedade à defesa de um bem social que são as universidades públicas. Pois para almejar o desenvolvimento regional, a expansão deve seguir acompanhada de investimentos e avaliação para manutenção de um ensino de qualidade. 
Finalizando, é possível perceber o relevante papel social da UFRRJ no município de Nova Iguaçu e na Baixada Fluminense. O sonho da universidade pública, gratuita e de qualidade se consolidava. Mas, caminhar é preciso e a universidade historicamente vem consolidando suas ações educativas e contribuindo para o desenvolvimento social, educacional e político da sociedade.

\section{REFERÊNCIAS}

ASSOCIAÇÃO NACIONAL DOS DOCENTES DA EDUCAÇÃO SUPERIOR (ANDES-SN). A Contra-Reforma da Educação Superior: uma análise do ANDES-SN das principais iniciativas do governo de Lula da Silva. Brasília, ago., 2004.

BRASIL. CONGRESSO NACIONAL. Emendas ao orçamento federal do ano de 2004. Brasília, 2003. Disponível em: $<$ http://www.camara.gov.br/internet/comissao/index/mista/orca/orcamento/OR2004/Rel_setor/Setor06/Setorial_rel0 05.pdf>. Consulta em 28 nov. 2015.

BRASIL. PRESIDÊNCIA DA REPÚBLICA - GRUPO DE TRABALHO INTERMINISTERIAL. Bases para o enfrentamento da crise emergencial das universidades brasileiras e roteiro para a reforma da universidade brasileira. Brasília, 2003.

BRASIL. Ministério do Planejamento, Orçamento e Gestão. Secretaria de Orçamento Federal. Orçamentos da União exercícios financeiros 2002, 2003, 2004, 2005, 2006, 2007, 2008, 2009: projeto de lei orçamentária. Disponível em <http://www.orcamentofederal.gov.br/orcamentos-anuais> Acesso em 20 jun. 2015.

BRASIL. Ministério da Educação. Secretaria de Educação Superior (SESu). A democratização e expansão da Educação Superior no país 2003-2014. 2015. Disponível em: $<$ http://portal.mec.gov.br/index.php?option=com content \&view=article\&id=20954\&Itemid=1329>. Acesso em: 25 mar. 2015.

Ministério da Educação. Secretaria de Educação Superior (SESu). Portaria no 49, 08 de julho de 2005. Diário Oficial [da] República Federativa do Brasil, Poder Executivo, Brasília, DF, 11 jul. 2005. seção 1, p. 6.

Ministério da Educação. Instituto Nacional de Estudos e Pesquisas Educacionais (INEP). Censo da Educação Superior: 2003, 2004 e 2010.

CENTRO FEDERAL DE EDUCAÇÃO TECNOLÓGICA CELSO SUCKOW DA FONSECA, website da UnED Nova Iguaçu (CEFET/NI). Disponível em: <http://portal.cefet-ri.br/uned-nova-iguacu.html>. Acesso em 20 abr. 2015.

Plano de Desenvolvimento Institucional - PDI - 2005-2009. Rio de Janeiro, CEFET-RJ, 2005. Disponível em: < http://www.cefet-rj.br/index.php/2015-06-02-18-40-13〉 . Acesso em: 28 de out. 2015.

Plano de Desenvolvimento Institucional - PDI - 2010-2014. Rio de Janeiro, CEFET-RJ, 2010. Disponível em: 〈http://www.cefet-rj.br/index.php/2015-06-02-18-40-13〉 . Acesso em: 28 de out. 2015.

GIL, A. C. Métodos e técnicas de pesquisa social. - 6. ed. - São Paulo: Atlas, 2008

INSTITUTO FEDERAL DO RIO DE JANEIRO (IFRJ). Plano de Desenvolvimento Institucional - PDI - 2009-2013. Nilópolis, IFRJ, 2009. Disponível em: 〈http://www.ifrj.edu.br/webfm_send/492>. Acesso em: 28 out. 2015.

OTRANTO, Celia Regina. A reforma da educação superior do governo Lula da Silva: da inspiração à implantação. Reunião anual da ANPED, v. 29, p. 1-19, 2006.

OTRANTO, Célia Regina. A Criação do Instituto de Educação da Universidade Federal Rural do Rio de Janeiro. Trabalho apresentado no I Encontro de História da Educação do Estado do Rio de Janeiro - IEHERJ. Niterói-RJ: UFF, 4 a 6 junho de 2007.

SIMÕES, M. R. A cidade estilhaçada: reestruturação econômica e emancipações municipais na Baixada Fluminense. 292 f. Tese (Doutorado em Geografia) - Universidade Federal Fluminense, Rio de Janeiro. 2007.

UNIVERSIDADE DO ESTADO DO RIO DE JANEIRO (UERJ) / FACULDADE DE EDUCAÇÃO DA BAIXADA FLUMINENSE (FEBF). Histórico da FEBF. Disponível em 〈http://www.febf.uerj.br/historico novo febf.html >. Consulta em 20 de abril de 2015. 
UNIVERSIDADE FEDERAL FLUMINENSE (UFF) / CONHECENDO A UFF. Conhecendo a UFF. Disponível em: <http://www.vestibular.uff.br/conhecendoaUFF.htm> Acesso em 20 abr. 2015.

UNIVERSIDADE FEDERAL RURAL DO RIO DE JANEIRO (UFRRJ). Plano de Desenvolvimento Institucional PDI - 2006-2010. Seropédica, UFRRJ, 2006. Disponível em: <http://institucional.ufrrj.br/pdi/>. Acesso em: 20 jun. 2015 .

Plano de Desenvolvimento Institucional - PDI - 2013-2017. Seropédica, UFRRJ, 2013. Disponível em: <http://institucional.ufrrj.br/pdi/>. Acesso em 20 jun. 2015.

Deliberação CONSU no 04 de 30 de março de 2006. Aprova o Projeto Político Pedagógico do Instituto Multidisciplinar da Universidade Federal Rural do Rio de Janeiro - Unidade Acadêmica desta Universidade em Nova Iguaçu. Disponível em: 〈http://www.ufrrj.br/soc/DOCS/deliberacoes/consu/Deliberacoes_2006/Delib04-2006.pdf>. Acesso em: 02 nov. 2015.

Portaria $\mathbf{n}^{\mathbf{0}}$ 788/GR, de 14 de outubro de 2005. Designa a prof ${ }^{\text {a }}$ Doutora Lucilia Augusta Lino de Paula como Diretora pro tempore do Instituto Multidisciplinar de Nova Iguaçu. Processo administrativo $\mathrm{n}^{\circ}$ 23083.004855/2005-55.

. Portaria n⿳ 802/GR, de 20 de setembro de 2006. Designa a prof ${ }^{\text {a }}$ Doutora Lucilia Augusta Lino de Paula como Diretora do Instituto Multidisciplinar de Nova Iguaçu para um mandato de quatro anos. Processo administrativo no $23083.004855 / 2005-55$.

. Convênio no 121/2005. Convênio que entre si celebram a União, representada pelo Ministério da Educação, por intermédio da Secretaria de Educação Superior (SESu), e a Universidade Federal Rural do Rio de Janeiro, para implantação do Campus de Nova Iguaçu da UFRRJ. Processo Administrativo nº 23083.004855/2005-55.

Rural Semanal $\mathbf{n}^{\mathbf{2}}$ 28. De outubro de 2004. Disponível em: <http://portal.ufrrj.br/institucional/imprensa/rural-semanal/>. Acesso em: 20 jun. 2015. 